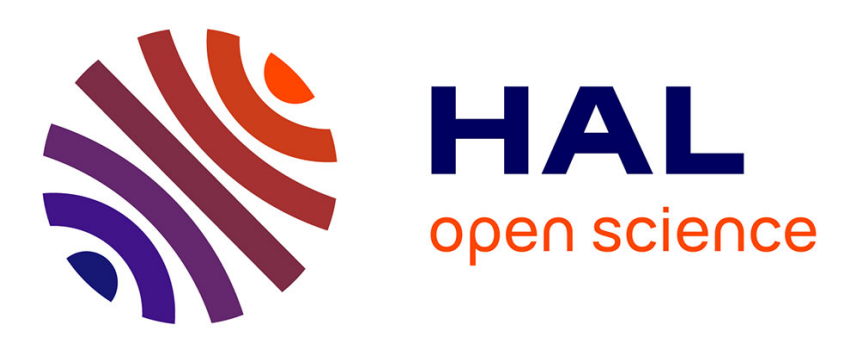

\title{
Ventilator-induced diaphragmatic dysfunction in MDX mice
}

Feng Liang, Tong Li, Ilan Azuelos, Christian Giordano, Han Liang, Sabah Hussain, Stefan Matecki, Basil Petrof

\section{- To cite this version:}

Feng Liang, Tong Li, Ilan Azuelos, Christian Giordano, Han Liang, et al.. Ventilator-induced diaphragmatic dysfunction in MDX mice. Muscle \& Nerve, 2018, 57 (3), pp.442-448. 10.1002/mus.25760 . hal-01791135

\section{HAL Id: hal-01791135 \\ https://hal.umontpellier.fr/hal-01791135}

Submitted on 22 Jan 2020

HAL is a multi-disciplinary open access archive for the deposit and dissemination of scientific research documents, whether they are published or not. The documents may come from teaching and research institutions in France or abroad, or from public or private research centers.
L'archive ouverte pluridisciplinaire HAL, est destinée au dépôt et à la diffusion de documents scientifiques de niveau recherche, publiés ou non, émanant des établissements d'enseignement et de recherche français ou étrangers, des laboratoires publics ou privés. 
FENG LIANG, PhD, ${ }^{1}$ TONG LI, PhD, ${ }^{1}$ ILAN AZUELOS, MD, ${ }^{1}$ CHRISTIAN GIORDANO, PhD, ${ }^{1}$ HAN LIANG, PhD, ${ }^{2,3}$

SABAH N. HUSSAIN, MD, PhD, ${ }^{1,4}$ STEFAN MATECKI, MD, PhD, ${ }^{5}$ and BASIL J. PETROF, MD ${ }^{1}$

${ }^{1}$ Meakins-Christie Laboratories, and Translational Research in Respiratory Diseases Program, McGill University Health Centre and Research Institute, 1001 Decarie Boulevard, Montreal, Quebec H4A 3J1, Canada

${ }^{2}$ Department of Bioinformatics and Computational Biology, University of Texas MD Anderson Cancer Center, Houston, Texas, USA

${ }^{3}$ Department of Systems Biology, University of Texas MD Anderson Cancer Center, Houston, Texas, USA

${ }^{4}$ Department of Critical Care, McGill University Health Centre, Montreal, Quebec, Canada

${ }^{5}$ Pediatric Functional Exploration Unit, University Hospital of Montpellier, UMR CNRS 9214-INSERM U1046, Université Montpellier, Montpellier, France

ABSTRACT: Introduction: Patients with Duchenne muscular dystrophy (DMD) frequently undergo mechanical ventilation (MV) for treatment of hypoventilation, but the susceptibility of the dystrophic diaphragm to ventilator-induced diaphragmatic dysfunction (VIDD) has not been examined. Methods: Dystrophic mice ( $m d x$ - genetic homolog of DMD) were assigned to non-ventilated control (CTL) and MV (for 6 hours) groups. Biochemical markers of oxidative/cellular stress, metabolism, and proteolysis were compared along with ex-vivo diaphragmatic force production. Results: MV significantly depressed maximal diaphragmatic force production compared with baseline values. In addition, MV triggered oxidative stress responses, STAT3 phosphorylation, and an upregulation of cellular pathways associated with muscle proteolysis and/or wasting (autophagy, E3 ubiquitin ligases, and myostatin). Discussion: Short-term MV induces rapid diaphragmatic force loss and biochemical changes consistent with VIDD in $m d x$ mice. This may have implications for the optimal use of intermittent MV in DMD patients.

\section{$\mathbf{V}_{\mathrm{e}}$} entilator-induced diaphragmatic dysfunction (VIDD) refers to a loss of diaphragmatic forcegenerating capacity specifically related to the use of mechanical ventilation (MV). ${ }^{1,2}$ In experimental animals, multiple studies have shown that controlled MV (i.e., without spontaneous respiratory

\begin{abstract}
Abbreviations: AMP, activated protein kinase; AMPK, autophagy-related gene, ATG; BNIP, Bcl2/adenovirus E1B 19-kDa interacting protein; CPT, carnitine palmitoyl transferase; CEBP, CCAAT/enhancer binding protein; CTL, control; DMD, Duchenne muscular dystrophy; FASN, fatty acid synthase; GABARAPL1, GABA(A) receptor-associated protein-like 1; HIF hypoxia-inducible factor; HPRT1, hypoxanthine phosphoribosyltransferase; IL-6, interleukin-6; MV, mechanical ventilation; LC3, microtubule-associated protein 1 light chain 3; mGPAT, mitochondrial glycerol-3-phosphate acyltransferase; MuRF1, muscle RING-finger protein-1; MSTN, myostatin; qPCR, quantitative polymerase chain reaction; STAT, signal transducer and activator of transcription; SIRT, sirtuin; SCD, stearoyl-coenzyme A desaturase; SREBF, sterol regulatory element binding transcription factor; SCAP, cleavage-activating protein; SOCS, suppressor of cytokine signaling; UVRAG, ultraviolet radiation resistance-associated gene; VIDD, ventilator-induced diaphragmatic dysfunction

Key words: diaphragm disuse; Duchenne muscular dystrophy; home mechanical ventilation; $m d x$ mice; neuromuscular disorder; VIDD

This work was supported by the Canadian Institutes of Health Research $(\mathrm{ClHR})$, Fonds de recherche du Quebec - Santé (FRQS), the McGill University Health Centre and Research Institute, and the JT Costello Memorial Fund.
\end{abstract}

Correspondence to: B.J. Petrof; e-mail: basil.petrof@mcgill.ca efforts) leads to an early decrease in the intrinsic force-generating capacity of diaphragm muscle fibers, which is then followed by the development of atrophy leading to even greater muscle weakness. In previously healthy animals the onset of VIDD is remarkably rapid, occurring within 12 hours after initiating MV., ${ }^{1,2}$ The evidence for VIDD in humans, derived primarily from critically ill patients with acute respiratory failure, ${ }^{3-6}$ is largely consistent with animal model findings. ${ }^{2}$

The extent to which VIDD occurs in the context of pre-existent neuromuscular pathology is entirely unknown. Intermittent $\mathrm{MV}$ is a wellestablished therapy for patients with chronic ventilatory insufficiency caused by neuromuscular diseases affecting the diaphragm and other respiratory muscles. In many patients, the occurrence of hypoventilation is initially limited to sleep, such that MV is only employed during the nighttime. Some investigators have reported that use of a controlled mode of non-invasive MV (i.e., with the lowest level of spontaneous respiratory effort possible) during sleep has advantages in terms of reduced apneas, ${ }^{7}$ greater correction of hypercapnia, ${ }^{8}$ and better adherence to therapy. ${ }^{9}$ However, it has not been determined whether such an approach is beneficial or harmful in patients with neuromuscular complications. Indeed, there are few data available to support any particular mode or target level of respiratory muscle effort during nocturnal MV in neuromuscular patients. ${ }^{10}$

The principal objective of this study was to determine whether controlled MV applied for 6 hours (a duration similar to that of nocturnal MV in patients) induces VIDD in a well-established animal model of neuromuscular disease, the $m d x$ mouse [genetic homolog of Duchenne muscular dystrophy $(\mathrm{DMD})^{11}$. We hypothesized that characteristic features of VIDD, consisting of diaphragm muscle weakness and activation of cellular pathways [e.g., oxidative stress, signal transducer and activator of transcription (STAT) 3 phosphorylation, altered lipid metabolism, and upregulation of muscle wasting genes-see ref. 12 for review], 
would occur in the diaphragms of $m d x$ mice undergoing short-term controlled MV. DMD is the most frequent childhood-onset form of muscular dystrophy and leads to a progressive loss of respiratory muscle strength with an attendant requirement for home MV by early adulthood. Therefore, establishing proof-of-concept that short-term MV can potentially induce deleterious effects on the diaphragm in DMD could have significant clinical implications.

\section{METHODS}

Animals and Mechanical Ventilation. Male $m d x$ mice were studied at 10-12 weeks of age and randomly assigned to either control (CTL) or MV groups. At this age, $m d x$ mice have established diaphragmatic inflammation, fibrosis, and weakness. ${ }^{11}$ All MV group mice were exposed to 6 hours of MV, using a protocol shown to induce VIDD in non-dystrophic mice that we have previously described in detail. ${ }^{13}$ CTL group animals did not undergo MV but were fasted for 6 hours before killing to replicate the lack of caloric intake in mice undergoing MV. The MV parameters and anesthesia were adjusted to prevent spontaneous breathing efforts as assessed by thoracoabdominal motion and bubbling pattern of the underwater seal. Before the experiments, the mice were housed, bred, and maintained in a barrier facility unit under specific pathogen-free conditions with a 12-hour light/dark cycle and access to food and water ad libitum. All aspects of the study were approved by the institutional animal care and use committee of the McGill University Health Centre.

Diaphragm Contractility. Contractile force measurements of electrically stimulated excised diaphragmatic strips were performed immediately after animal euthanasia, with the operator blinded to experimental group identity. The force-frequency relationship (at 10, 30, 50, 100, and $150 \mathrm{~Hz}$ ) was determined in a temperature-controlled jacketed tissue bath chamber, as we have previously described in detail. ${ }^{6,14}$ Muscle force was normalized to tissue crosssectional area, which was determined assuming a muscle density of $1.056 \mathrm{~g} / \mathrm{cm}^{3}$.

Immunoblotting. Antibody dilutions were prepared according to the manufacturers' instructions. Quantification of protein bands was performed using the Odyssey Infrared Imaging System (LI-COR Biosciences, Lincoln, Nebraska), with Ponceau red to adjust for protein loading. The following proteins were detected: LC3B (clone D11; Cell Signaling, Danvers, Massachusetts); p62/SQSTM1 (clone 2C11; Novus Biologicals, Littleton, Colorado); total and phosphorylated (Tyr705) forms of STAT3 (clones 124H6 and D3A7; Cell Signaling); calpain 1 (clone 15C10; Sigma Co., St. Louis, Missouri); and carbonylated proteins (Oxyblot Protein Oxidation Detection Kit; EMD Millipore, Darmstadt, Germany).

\section{Real-time Quantitative Polymerase Chain Reaction.}

Real-time quantitative polymerase chain reaction (qPCR) was performed using the StepOne Plus system (Applied Biosystems, Waltham, Massachusetts). Relative messenger RNA (mRNA) level quantifications of target genes in the MV group were determined using the cycle threshold method with hypoxanthine phosphoribosyltransferase (HPRT1) as
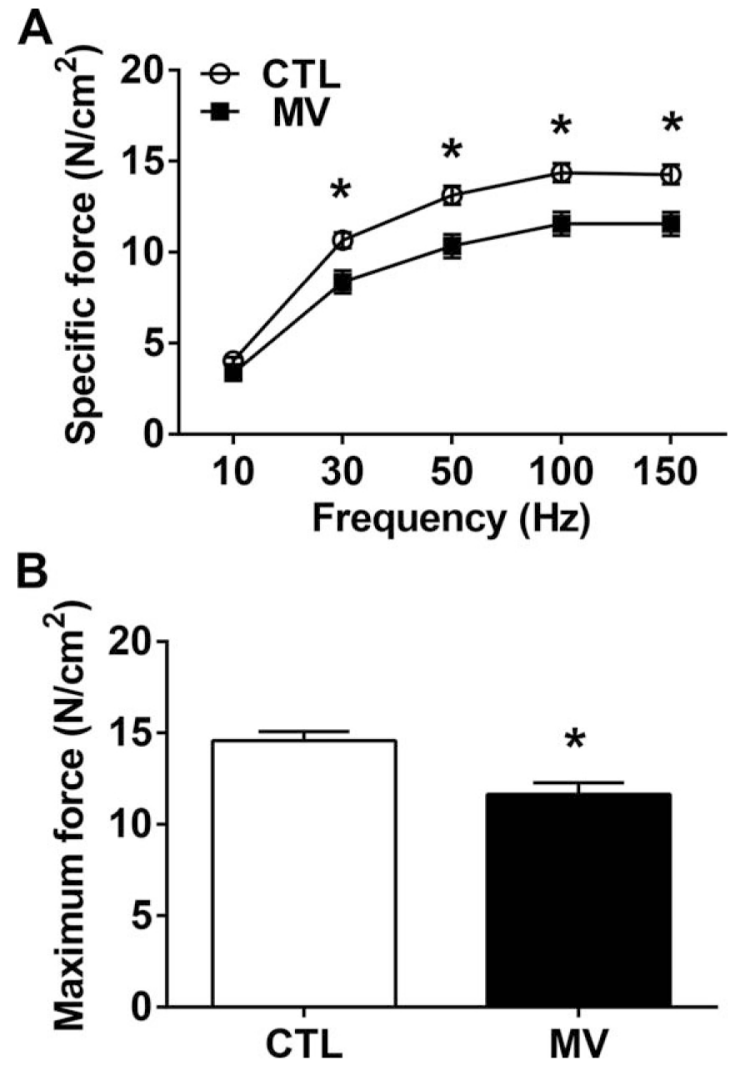

FIGURE 1. Diaphragmatic force loss after MV. (A) Force-frequency relationship of the diaphragm determined ex vivo and (B) maximum isometric force. ${ }^{*} P<0.05$ for control (CTL) vs. mechanical ventilation (MV) groups ( $n=15$ per group).

the housekeeping gene, and the data were expressed as fold-change relative to the comparison group. Primer sequences are shown in Table S1 (refer to Supplementary Material available online).

Statistical Analysis. To obtain an overview of candidate gene expression changes associated with MV in $m d x$ diaphragms, an unsupervised hierarchical clustering analysis (Ward algorithm, Spearman rank-based distance) was applied to the mRNA transcript data for metabolic stress, autophagy, lipid metabolism, STAT3-related, and musclewasting genes. A heatmap was generated using $\mathrm{R}$ software version 2.12.1 (R Statistical Computing, Vienna, Austria), ${ }^{15}$ and values for the clustering analysis were normalized to the mean of controls. Other data are expressed as mean \pm SEM and differences analyzed using a standard 2-tailed $t$-test (assuming unpaired data sets and unequal variances) or 2way analysis of variance (GraphPad Prism, GraphPad, San Diego, California). Statistical significance was defined as $P<0.05$ for all tests. The sample size estimates were based on previously published force generation and gene expression data obtained in wild-type mice subjected to $\mathrm{MV},{ }^{13}$ and were designed to detect a $20 \%$ change in maximal force and 2-fold change in gene expression ( $\alpha$ level set at 0.05, with power at 0.80 ).

\section{RESULTS}

Loss of Maximal Force after $M V$ in Dystrophic Diaphragms. There was a significant depression of force production by the diaphragm at most 


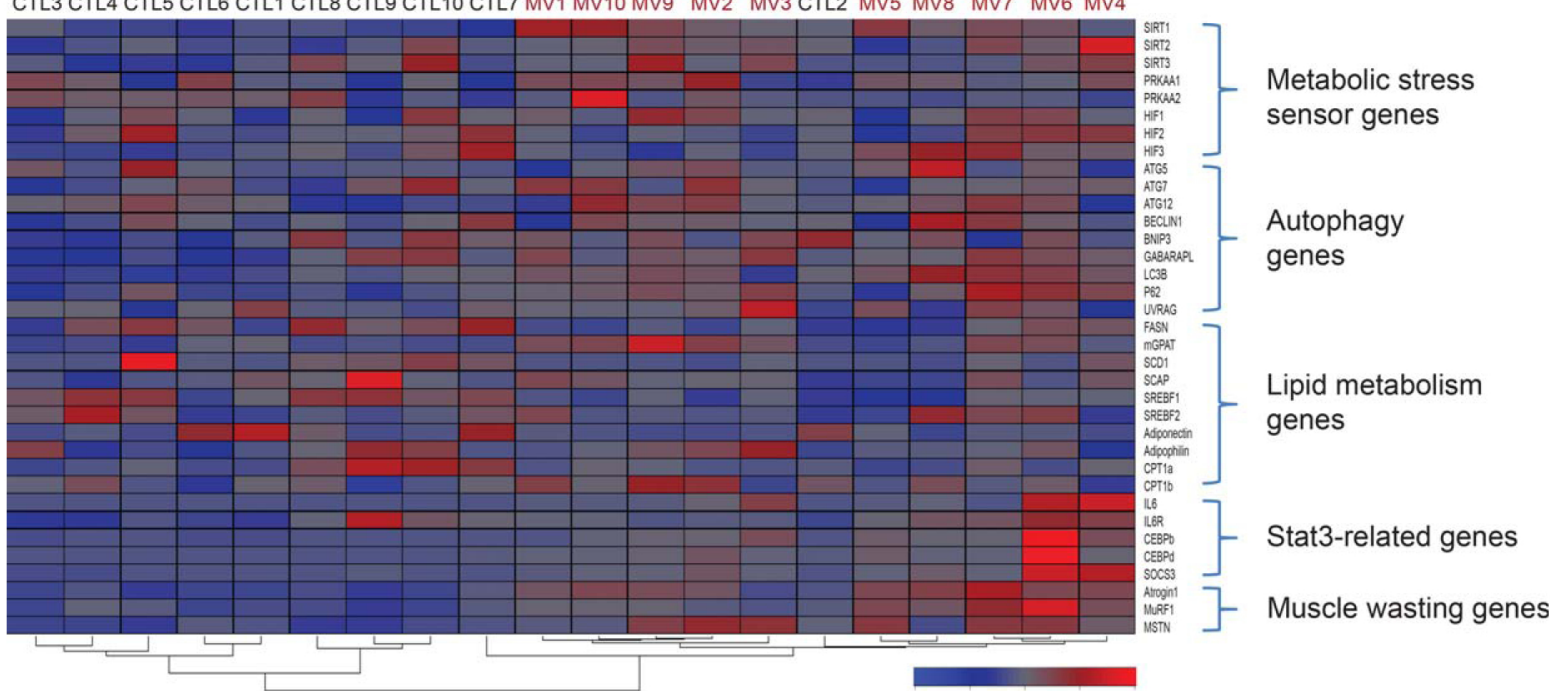

FIGURE 2. Hierarchical clustering analysis of gene signature response to MV. Heatmap depicting relative levels of gene expression (blue= lower expression; red = higher expression); the branching dendrogram below the heatmap identifies the gene clustering pattern (shorter vertical branches indicating greater similarity). Gene expression values were transformed to Z-scores for visualization. A significant $(P=0.0007)$ cluster separation was found between control (CTL) and mechanical ventilation (MV) diaphragms $(n=10$ per group)

electrical stimulation frequencies after use of MV for 6 hours in the $m d x$ mice (Fig. 1A). The postMV decline in maximal diaphragmatic force relative to baseline values amounted to a mean decrease of approximately $19 \%$ (Fig. 1B).

\section{Changes in Expression of Multiple VIDD-Associated}

Genes and Proteins. As shown in Figure 2, unbiased hierarchical clustering analysis revealed 2 major gene clusters corresponding to the CTL and MV groups, with a high level of statistical significance $(P=0.0007)$. As indicators of metabolic stress, we assessed transcript levels of several key metabolic sensors: sirtuins (SIRTs); AMP-activated protein kinase (AMPK) subunits (PRKAAs); and hypoxia-inducible factors (HIFs). There was a significant increase of SIRT1 expression, whereas the other metabolic stress markers remained unchanged (Fig. 3A). In $m d x$ diaphragms subjected to $\mathrm{MV}$, there was also increased mitochondrial glycerol-3-phosphate acyltransferase (mGPAT) expression, accompanied by decreased levels of sterol regulatory element binding transcription factor 1 (SREBF1) and adiponectin (Fig. 3B). The effects of MV on metabolic stress responses were also examined at the protein level. There was a significant elevation in diaphragm protein carbonylation after 6 hours of MV in $m d x$ mice (Fig. 3C), which is consistent with the presence of increased oxidative stress.

There was also increased expression of prototypical STAT3-associated genes after MV (Fig. 4A), which was particularly striking in the case of interleukin-6 (IL-6, elevated approximately 30fold). In keeping with these findings, $m d x$ diaphragms subjected to MV contained substantially increased (approximately 4-fold) levels of phosphorylated STAT3 (p-STAT3) protein (Fig. 4B).

Effects of MV on Muscle Proteolysis Pathways. There was a reduction in protein levels of lipidated LC3B (LC3-II) after MV (Fig. 5A), while at the same time mRNA transcript levels for the autophagyassociated genes GABARAPL1, LC3B, and p62/ SQSTM1 were all increased significantly in the MV group (Fig. 5B). Absolute levels of active (cleaved) calpain 1 protein did not change after MV for 6 hours (Fig. 6A). In contrast, atrogin 1, MuRF1, and myostatin (MSTN) transcripts were all increased significantly (Fig. 6B).

\section{DIscussion}

The present study was designed to address the question of whether short-term MV leads to diaphragmatic dysfunction (i.e., VIDD) in the setting of an underlying neuromuscular pathology such as DMD. The $m d x$ mouse is the most commonly used animal model of DMD, and its diaphragm exhibits necrosis, fibrosis, and muscle weakness in a manner closely resembling the human disease. ${ }^{11}$ Previous work in non-dystrophic animals has demonstrated that VIDD is associated with a series of characteristic biochemical and gene expression changes in the diaphragm. These include: (1) signs of oxidative/ metabolic stress; (2) activation of STAT3; and (3) upregulation of genes linked to different forms of muscle proteolysis. ${ }^{2,12}$ We have previously used the 
dystrophic mice is associated with prevention of diaphragmatic weakness during the early stages of VIDD. ${ }^{14}$ Therefore, activation of autophagy could potentially help to mitigate $\mathrm{MV}$-induced force loss in the dystrophic diaphragm, although this hypothesis requires formal testing in future studies.

In addition to autophagy, other genes involved in muscle proteolysis and previously found to be activated in the diaphragm during $\mathrm{MV}$ were also evaluated. In this regard, calpain 1 activation has been implicated in DMD pathogenesis ${ }^{32}$ as well as VIDD. ${ }^{33}$ This was unaffected by short-term MV in $m d x$ mice, although we cannot exclude the possibility that our study was underpowered with respect to this outcome. On the other hand, shortterm MV triggered significant upregulation of MSTN, which is not only capable of reducing skeletal muscle protein synthesis but can also activate atrogin 1 and MuRF1. ${ }^{34}$ The latter muscle-specific E3 ubiquitin ligases were significantly upregulated in $m d x$ diaphragms subjected to MV and have previously been implicated in the development of VIDD in healthy animals. ${ }^{35,36}$

The probability of VIDD occurring in human DMD patients undergoing $\mathrm{MV}$ is currently unknown, and hence the clinical importance of our findings is yet to be determined. Although baseline force-generating capacity of the $m d x$ diaphragm was significantly reduced compared with healthy diaphragms, the magnitude of MVassociated force loss in $m d x$ diaphragms (approximately $19 \%$ ) was slightly less than that observed in our previous studies of non-dystrophic mice (approximately 25\%-30\%) subjected to the same duration of MV. ${ }^{6,14}$ Furthermore, it can be reasonably argued that once respiratory muscle weakness has advanced to the point of causing chronic hypoventilation in DMD patients, any adverse effects of MV on diaphragmatic function are outweighed by its benefits. These benefits can include better daytime functioning and sleep quality as well as an improvement in overall quality of life. Current clinical guidelines recommend that nocturnal MV be instituted in DMD patients once major or symptomatic hypoventilation has developed during sleep. ${ }^{10}$ However, there remains a gray zone of uncertainty about the optimal timing for initiating MV in asymptomatic patients with only mild levels of nocturnal hypercapnia. ${ }^{37}$ It is in this latter group of DMD patients that the occurrence of VIDD may be of greatest clinical relevance. Indeed, older clinical trial data in DMD patients show that early "preventive" introduction of MV was associated with increased mortality, although effects on diaphragmatic function and the mechanisms responsible for increased deaths in the MV group were not determined. ${ }^{38}$
Given that intermittent $\mathrm{MV}$ is ultimately required for many DMD patients, our findings suggest that various proposed countermeasures to VIDD should be further explored in this population. This may well include ensuring adequate spontaneous respiratory efforts during $\mathrm{MV}$, and there are currently no specific recommendations regarding a target level of respiratory muscle effort during nocturnal ventilation of DMD patients. Our study employed controlled $\mathrm{MV}$ to minimize diaphragmatic activity to the greatest extent possible, which likely reflects a worst-case scenario with respect to the risk of developing VIDD. ${ }^{39}$ Daytime respiratory muscle training or drug therapies directed at cellular pathways implicated in VIDD (see ref. 12 for review) could be particularly useful in the DMD context, as many of the same mechanisms associated with VIDD (e.g., oxidative stress, mitochondrial dysfunction, etc.) are also implicated in DMD pathogenesis.

In conclusion, in this study we have demonstrated both functional and biochemical evidence for the development of VIDD after 6 hours of MV in $m d x$ mice. The probability of VIDD occurring in human DMD patients undergoing MV in the clinical setting remains unknown and our findings suggest that this is an important issue that deserves further study.

\section{REFERENCES}

1. Vassilakopoulos T, Petrof BJ. Ventilator-induced diaphragmatic dysfunction. Am J Respir Crit Care Med 2004;169:336-341.

2. Jaber S, Jung B, Matecki S, Petrof BJ. Clinical review: ventilatorinduced diaphragmatic dysfunction-human studies confirm animal model findings! Crit Care 2011;15:206.

3. Levine S, Nguyen T, Taylor N, Friscia ME, Budak MT, Rothenberg P, et al. Rapid disuse atrophy of diaphragm fibers in mechanically ventilated humans. N Engl J Med 2008;358:1327-1335.

4. Hussain SNA, Mofarrahi M, Sigala I, Kim HC, Vassilakopoulos T, Maltais F, et al. Mechanical ventilation-induced diaphragm disuse in humans triggers autophagy. Am J Respir Crit Care Med 2010;182: $1377-1386$.

5. Jaber S, Petrof BJ, Jung B, Chanques G, Berthet J-P, Rabuel C, et al. Rapidly progressive diaphragmatic weakness and injury during mechanical ventilation in humans. Am J Respir Crit Care Med 2011; 183:364-371.

6. Picard M, Jung B, Liang F, Azuelos I, Hussain S, Goldberg P, et al. Mitochondrial dysfunction and lipid accumulation in the human diaphragm during mechanical ventilation. Am J Respir Crit Care Med 2012;186:1140-1149.

7. Contal O, Adler D, Borel J-C, Espa F, Perrig S, Rodenstein D, et al. Impact of different backup respiratory rates on the efficacy of noninvasive positive pressure ventilation in obesity hypoventilation syndrome: a randomized trial. Chest 2013;143:37-46.

8. Dellweg D, Schonhofer B, Haidl PM, Barchfeld T, Wenzel MD, Appelhans $\mathrm{P}$, et al. Short-term effect of controlled instead of assisted noninvasive ventilation in chronic respiratory failure due to chronic obstructive pulmonary disease. Respir Care 2007;52:1734-1740.

9. Tsuboi T, Oga T, Machida K, Chihara Y, Matsumoto H, Niimi A, et al. Importance of ventilator mode in long-term noninvasive positive pressure ventilation. Respir Med 2009;103:1854-1861.

10. McKim DA, Road J, Avendano M, Abdool S, Cote F, Duguid N, et al. Home mechanical ventilation: a Canadian Thoracic Society clinical practice guideline. Can Respir J 2011;18:197-215.

11. Stedman HH, Sweeney HL, Shrager JB, Maguire HC, Panettieri RA, Petrof $\mathrm{B}$, et al. The mdx mouse diaphragm reproduces the degenerative changes of Duchenne muscular dystrophy. Nature 1991;352:536539

12. Petrof BJ, Hussain SN. Ventilator-induced diaphragmatic dysfunction: what have we learned? Curr Opin Crit Care 2016;22:67-72. 

13. Mrozek S, Jung B, Petrof BJ, Pauly M, Roberge S, Lacampagne A,
et al. Rapid onset of specific diaphragm weakness in a healthy murine model of ventilator-induced diaphragmatic dysfunction. Anesthesiology 2012;117:560-567.

14. Azuelos I, Jung B, Picard M, Liang F, Li T, Lemaire C, et al. Relationship between autophagy and ventilator-induced diaphragmatic dysfunction. Anesthesiology 2015;122:1349-1361.

15. Zolla-Pazner S, deCamp A, Gilbert PB, Williams C, Yates NL, Williams WT, et al. Vaccine-induced IgG antibodies to V1V2 regions of multiple HIV-1 subtypes correlate with decreased risk of HIV-1 infection. PLoS One 2014;9:e87572.

16. Lu J, Getz G, Miska EA, Alvarez-Saavedra E, Lamb J, Peck D, et al. MicroRNA expression profiles classify human cancers. Nature 2005; 435:834-838.

17. Makretsov NA, Huntsman DG, Nielsen TO, Yorida E, Peacock M Cheang MCU, et al. Hierarchical clustering analysis of tissue microarray immunostaining data identifies prognostically significant groups of breast carcinoma. Clin Cancer Res 2004;10:6143-6151.

18. Powers SK, Hudson MB, Nelson WB, Talbert EE, Min K, Szeto HH, et al. Mitochondria-targeted antioxidants protect against mechanical ventilation-induced diaphragm weakness. Crit Care Med 2011;39: $1749-1759$

19. Picard M, Azuelos I, Jung B, Giordano C, Matecki S, Hussain S, et al. Mechanical ventilation triggers abnormal mitochondrial dynamics and morphology in the diaphragm. J Appl Physiol 2015;118:11611171.

20. Garama DJ, White CL, Balic JJ GD. Mitochondrial STAT3: powering up a potent factor. Cytokine 2016;87:20-25.

21. Smith IJ, Godinez GL, Singh BK, McCaughey KM, Alcantara RR, Gururaja $\mathrm{T}$, et al. Inhibition of Janus kinase signaling during controlled mechanical ventilation prevents ventilation-induced diaphragm dysfunction. FASEB J 2014;28:2790-2803.

22. Tang H, Smith IJ, Hussain SNA, Goldberg P, Lee M, Sugiarto S, et al The JAK-STAT pathway is critical in ventilator-induced diaphragm dysfunction. Mol Med 2014;20:579-589.

23. Tanno M, Kuno A, Yano T, Miura T, Hisahara S, Ishikawa S, et al. Induction of manganese superoxide dismutase by nuclear translocation and activation of SIRT1 promotes cell survival in chronic heart failure. J Biol Chem 2010;285:8375-8382.

24. Hsu C-P, Zhai P, Yamamoto T, Maejima Y, Matsushima S, Hariharan $\mathrm{N}$, et al. Silent information regulator 1 protects the heart from ische$\mathrm{mia}$ /reperfusion. Circulation 2010;122:2170-2182.

25. Pardo PS, Mohamed JS, Lopez MA, Boriek AM. Induction of Sirt1 by mechanical stretch of skeletal muscle through the early response factor EGR1 triggers an antioxidative response. J Biol Chem 2011;286: $2559-2566$.

26. Yang Y, Duan W, Lin Y, Yi W, Liang Z, Yan J, et al. SIRT1 activation by curcumin pretreatment attenuates mitochondrial oxidative damage induced by myocardial ischemia reperfusion injury. Free
Radic Biol Med 2013;65:667-79.

27. Kuno A, Horio Y. SIRT1: a novel target for the treatment of muscular dystrophies. Oxid Med Cell Longev 2016;2016:6714686.

28. Hammond LE, Albright CD, He L, Rusyn I, Watkins SM, Doughman $\mathrm{SD}$, et al. Increased oxidative stress is associated with balanced increases in hepatocyte apoptosis and proliferation in glycerol-3phosphate acyltransferase-1 deficient mice. Exp Mol Pathol 2007;82: 210-219.

29. Youle RJ, Narendra DP. Mechanisms of mitophagy. Nat Rev Mol Cell Biol 2011;12:9-14.

30. De Palma C, Morisi F, Cheli S, Pambianco S, Cappello V, Vezzoli M, et al. Autophagy as a new therapeutic target in Duchenne muscular dystrophy. Cell Death Dis 2012;3:e418.

31. Pauly M, Daussin F, Burelle Y, Li T, Godin R, Fauconnier J, et al AMPK activation stimulates autophagy and ameliorates muscular dystrophy in the mdx mouse diaphragm. Am J Pathol 2012;181:583-592.

32. Selsby J, Pendrak K, Zadel M, Tian Z, Pham J, Carver T, et al. Leupeptin-based inhibitors do not improve the mdx phenotype. Am J Physiol Regul Integr Comp Physiol 2010;299:R1192-201.

33. Maes K, Testelmans D, Powers S, Decramer M, Gayan-Ramirez G. Leupeptin inhibits ventilator-induced diaphragm dysfunction in rats. Am J Respir Crit Care Med 2007;175:1134-1138.

34. Gallot YS, Durieux A-C, Castells J, Desgeorges MM, Vernus B, Plantureux L, et al. Myostatin gene inactivation prevents skeletal muscle wasting in cancer. Cancer Res 2014;74:7344-7356.

35. Agten A, Maes K, Thomas D, Cielen N, Van Hees HWH, Dekhuijzen RPN, et al. Bortezomib partially protects the rat diaphragm from ventilator-induced diaphragm dysfunction. Crit Care Med 2012;40: 2449-2455.

36. Hooijman PE, Beishuizen A, Witt CC, de Waard MC, Girbes ARJ, Spoelstra-de Man AME, et al. Diaphragm muscle fiber weakness and ubiquitin-proteasome activation in critically ill patients. Am J Respir Crit Care Med 2015;191:1126-1138.

37. Ward S, Chatwin M, Heather S, Simonds AK. Randomised controlled trial of non-invasive ventilation (NIV) for nocturnal hypoventilation in neuromuscular and chest wall disease patients with daytime normocapnia. Thorax 2005;60:1019-1024.

38. Raphael JC, Chevret S, Chastang C, Bouvet F. Randomised trial of preventive nasal ventilation in Duchenne muscular dystrophy. French Multicentre Cooperative Group on Home Mechanical Ventilation Assistance in Duchenne de Boulogne Muscular Dystrophy. Lancet 1994:343:1600-1604.

39. Hudson MB, Smuder AJ, Nelson WB, Bruells CS, Levine S, Powers SK. Both high level pressure support ventilation and controlled mechanical ventilation induce diaphragm dysfunction and atrophy. Crit Care Med 2012;40:1254-1260. 